\title{
Side effects of antidepressants during long-term use in a naturalistic setting
}

\author{
Pierre M. Bet ${ }^{a, b, *}$, Jacqueline G. Hugtenburg ${ }^{a, c}$, \\ Brenda W.J.H. Penninx ${ }^{b, c, d, e, f}$, Witte J.G. Hoogendijk ${ }^{b, d, g}$
}

\author{
a Department of Clinical Pharmacology and Pharmacy, VU University Medical Center, De Boelelaan 1117, \\ 1081 HV Amsterdam, the Netherlands \\ ${ }^{\mathrm{b}}$ Neuroscience Campus Amsterdam, VU University, Amsterdam, the Netherlands \\ ${ }^{c} E M G O$ Institute, VU University Medical Center, Amsterdam, the Netherlands \\ ${ }^{\mathrm{d} D e p a r t m e n t}$ of Psychiatry, VU University Medical Center, Amsterdam, the Netherlands \\ 'Department of Psychiatry, University Medical Center Groningen, University of Groningen, Groningen, \\ the Netherlands \\ ${ }^{f}$ Department of Psychiatry, University Medical Center, Leiden, the Netherlands \\ ${ }^{g}$ Department of Psychiatry, Erasmus Medical Center, Rotterdam, the Netherlands
}

Received 14 November 2012; received in revised form 11 March 2013; accepted 4 May 2013

\section{KEYWORDS \\ Side effects; \\ Antidepressants; \\ Depression; \\ Anxiety; \\ Naturalistic setting}

\begin{abstract}
Side effects of antidepressants are usually underreported in clinical trials and large scale naturalistic studies are restricted to six months of use. We examined the prevalence and nature of patient-perceived side effects and their determinants during long-term antidepressant use in a naturalistic setting. Subjects, aged 19 to 67 years, in the Netherlands Study of Depression and Anxiety were recruited from primary care and specialized mental health care covered 927 cases of single antidepressant use. In $64 \%$ of cases, on average, 2.9 side effects were reported. The number of side effects was higher when subjects had higher depression severity $(O R=1.28$; $p=0.002)$, three or more psychiatric diagnoses $(\mathrm{OR}=1.97 ; p=0.02)$, higher dose $(\mathrm{O}=1.44$; $p=0.006)$ and was lower when subjects were older $(\mathrm{OR}=0.83 ; p=0.02)$ and had longer duration of use $(\mathrm{OR}=0.94 ; p=0.04)$. Tricyclic antidepressants were associated with more side effects $(\mathrm{OR}=2.52 ; p=0.003)$ and, particularly, more anticholinergic effects, like dry mouth and constipation, as compared to selective serotonin reuptake inhibitors. Venlafaxine showed more profuse sweating $(O R=1.79 ; p=0.007)$, whereas mirtazapine showed more weight gain and less sexual dysfunction $(\mathrm{OR}=0.36 ; p=0.03)$, as compared to selective serotonin reuptake inhibitors. Weight gain was associated with female gender $(O R=1.76 ; p=0.004)$ and duration of use $(O R=1.06 ; p=0.03)$. We show that antidepressant side effect, known from short-term studies, persist during long-term use and are associated with depression severity and antidepressant dose.
\end{abstract}

\footnotetext{
*Corresponding author at: Department of Clinical Pharmacology and Pharmacy, VU University Medical Center, De Boelelaan 1117, 1081 HV Amsterdam, The Netherlands. Tel.: +31 20 44435546; fax: +31 204443525.
}

E-mail address: pm.bet@vumc.nl (P.M. Bet). 
A novel finding was that venlafaxine is associated with more profuse sweating and that weight gain appeared more specific in female users. Clinicians should be aware that, during long-term antidepressant use, side effects are common and persistent. (c) 2013 Elsevier B.V. and ECNP. All rights reserved.

\section{Introduction}

Antidepressant use is associated with a variety of side effects (SEs). In clinical trials their prevalence is up to $27 \%$ (Trindade et al., 1998). SEs interfere with optimal treatment dosages and may be the cause of medication non-adherence and discontinuation (Lingam and Scott, 2002). Although SEs should be known before an antidepressant is introduced in daily practice, SE assessment in clinical trials concerning mental health is inadequate, particularly with respect to long-term effects (Papanikolaou et al., 2004). A recent large scale metaanalysis of 143 clinical trials on antidepressants showed that structured and systematic SE assessment strategies were used in only $21 \%$ of these trials (Rief et al., 2009). Moreover, a systematic review on 115 studies revealed that only a few trials used an objective side effect rating scale whereas adverse events were rarely pre-specified and defined (Gartlehner et al., 2008). In clinical trials often only shortterm severe SEs are reported. This lack of adequate SE data is hindering the evaluation of antidepressant risk-benefit ratios (Papanikolaou et al., 2004).

Although participants of antidepressant clinical trials represent only a small highly selected minority of depressed patients in clinical practice, trial results on efficacy can be generalized to the general population (van der Lem et al., 2011; Zimmerman et al., 2002). Clinical trials have revealed differences in SE profiles among different types of antidepressants (Anderson, 2000; Trindade et al., 1998; Watanabe et al., 2010; Stahl et al., 2005; Gartlehner et al., 2008). However, it is not clear whether there is similarity between SEs reported in clinical trials and those occurring in daily practice (van der Lem et al., 2011; Zimmerman et al., 2002). Prescription Event Monitoring has provided naturalistic SE data in a primary care setting of short-term (up to 6 months) antidepressant use (Mackay et al., 1997; Mann et al., 1997; Mackay et al., 1999), but antidepressant-induced SE data in a long-term naturalistic setting is lacking.

Little is known about the persistence of patientperceived SEs during long-term antidepressant use. In a large short-term study comparing citalopram and nortriptyline most SEs, which were assessed on a weekly basis, decreased over a 12 week study period (Uher et al., 2009). The clinical notion that SEs wear off during prolonged use over years is not substantiated with data. The mean incidence of headache and nausea in 27 antidepressant continuation- and maintenance-phase studies was $16 \%$ and $7 \%$, respectively. Compared to acute phase studies, the relative incidence of these events was only slightly lower (Hansen et al., 2008). Finally, reports of long-term clinical trials also seldom provide differentiation between SE prevalence at the beginning of the trial and SE prevalence after 6-24 months of continued treatment (Kasper et al., 2008; Thase et al., 2011).
Patient-, disease- and treatment-related factors like age (Draper and Berman, 2008; Naranjo et al., 1995; Stone et al., 2009), depression severity (Wilting et al., 2009; Uher et al., 2009) and type and dose of antidepressant (Trindade et al., 1998; Watanabe et al., 2010; Stahl et al., 2005) influence the occurrence and severity of SEs in clinical trials. Because of unknown external validity of SE data from clinical trials to long-term daily use and the lack of systematic SE data comparing different antidepressants over an extended time course, it is important to study antidepressant-induced SEs during long-term use in a naturalistic setting. We therefore examined the prevalence, nature and determinants of SEs during long-term use of different types of antidepressants in a naturalistic setting.

\section{Experimental procedures}

\subsection{Study sample}

All subjects participating in the present study came from the Netherlands Study of Depression and Anxiety (NESDA), an ongoing longitudinal cohort study conducted among 2981 adult subjects (18-65 years) to examine (predictors of) the long-term course of depression and anxiety disorders. The rationales, methods and recruitment strategy have been described elsewhere (Penninx et al., 2008).

The NESDA sample consists of 652 persons without depression or anxiety disorders and 2329 with a (remitted or current) diagnosis of a depressive and/or anxiety disorder. In order to represent various settings and stages of psychopathology, depressed or anxious subjects were recruited at three different locations in the Netherlands in different settings: community, primary care, and specialized mental health care. Community-based subjects were previously identified in two population-based studies (Nemesis and Ariadne). Primary care subjects were identified through a 2-stage screening procedure (involving the K10 questionnaire (Kessler et al., 2002; Kessler et al., 2003) and the CIDI-SF [Composite International Diagnostic Interview, Short Form] telephone interview) conducted among patients of 65 general practitioners. Mental health care patients were recruited when newly admitted to one of the 17 participating mental health organizations. Subjects with clinically overt psychotic disorder, obsessive compulsive disorder, bipolar disorder, or severe addiction disorder were excluded. The study protocol was approved centrally by the Ethical Review Board of the VU University Medical Center and subsequently by local review boards of each participating center. All subjects signed an informed consent at baseline assessment.

NESDA subjects were enrolled between September 2004 and February 2007. One-year follow-up data were acquired by means of a written questionnaire $(n=2445)$ and the two-year follow up data were obtained by means of a face to face interview $(n=2596)$.

All subjects who reported using antidepressants or did so in the year preceding the first (1-year) and/or second (2-year) follow-up, were included in the study sample $(n=907)$. If subjects reported the same antidepressant at both assessments, we used the first assessment and excluded the second assessment in order not to bias the prevalence of side effects. Subjects using two antidepressants at 
the same time $(n=61)$ were excluded in order to avoid attribution of SEs to the wrong antidepressant. Eighty one subjects reported two different episodes of single antidepressant use. Therefore, our study sample consisted of 927 cases of antidepressant use within 846 subjects. Six hundred and twenty five cases originated from the one-year follow-up data and 302 cases from the two-year follow-up. Seventy six percent of the cases $(n=701)$ reported SEs on current use, the others reported SEs while not currently on medication anymore. All data was obtained at the time of the SE assessment.

\subsection{Medication use}

Current medication use including name, dose end daily amount of both psychotropic and non-psychotropic medication, was inventoried with the aid of the subjects' medication boxes. Medication use was checked whether the information provided was pharmaceutically possible. Duration of use of the antidepressant on which SEs were reported, was noted in months. We classified medications by using the World Health Organization Anatomical Therapeutic Chemical (ATC) system (WHO, 2012). We distinguished selective serotonin re-uptake inhibitors (SSRIs, ATC code N06AB), tricyclic antidepressants (TCAs, ATC code N06AA), venlafaxine (ATC code N06AX16), mirtazapine (ATC code N06AX11) and other antidepressants (including monoamine oxidase inhibitors, non-selective N06AF and antidepressants classified as N06AX, excluding N06AX11 and N06AX16). For all antidepressants a derived daily dose was calculated by dividing the subject's daily dose used by the defined daily dose (DDD) recommended by the WHO (WHO, 2012). Benzodiazepine use was determined by selecting ATC codes N03AE, N05BA, N05CD and N05CF.

\subsection{Side effects}

SEs were collected for every psychotropic drug, including alternative medicines like St John's wort, the subject used on a daily basis and for all psychotropic medication used in the last year. A short 12-question self-report Antidepressant Side Effect Checklist (ASEC-12) was constructed. Recently, the self-report ASEC-21 was validated (Uher et al., 2009) against the UKU Side Effect Rating Scale, a semistructured interview by a health professional (Lingjaerde et al., 1987). The ASEC-12 shortlist specifically asks for the presence of patient-perceived SEs, related to antidepressant therapy: insomnia, sleepiness during the day, restlessness, muscle spasms/twitching, dry mouth, profuse sweating, sexual disorders, nausea, constipation, diarrhea, weight gain and dizziness. We did not define a specific time period in which the SEs should have occurred and expect to measure current side effects or side effects that have occurred recently.

\subsection{Psychiatric status}

The presence of depressive and anxiety disorders in the preceding two years was assessed using the CIDI 2.1 psychiatric interview. The presence or absence of a major depressive disorder, minor depressive disorder, dysthymia, panic disorder (with or without agoraphobia), social phobia or generalized anxiety disorder was also assessed. The CIDI establishes diagnoses according to DSM-IV criteria (American Psychiatric Association, 2001) and has shown high inter-rater and test-retest reliability and high validity for depressive disorders (Wittchen, 1994). The severity of depression was evaluated using the 30-item Inventory of Depressive Symptoms self-report version (IDS-SR), which also includes various anxiety items (Rush et al., 1996). Alcohol dependence and alcohol abuse was assessed with the CIDI interview.

\subsection{Statistical analyses}

SE parameters were compared in the four groups of antidepressants, being SSRI, TCA, venlafaxine and mirtazapine $(n=884)$, excluding 'St John's wort' and 'other antidepressants'. The number of SEs per case were divided in three categories: 'no SEs', 'one or two SEs' and 'three or more SEs'. Overall $p$-values were calculated using $\chi^{2}$-statistics for the categories of the number of SEs and the presence of specific SEs. The four groups of antidepressants were individually compared with univariate analyses using $\chi^{2}$-statistics. $P$-value cut-offs of 0.05 were considered as significant.

In a multivariate analysis we included subject-related factors (gender, age, years of education), disease related factors (depression symptom severity, number of psychiatric diagnoses and benzodiazepine use) and antidepressant-related factors (type of antidepressant, dose and duration). The number of SEs, divided into the three categories, were analyzed using multinomial logistic regression analysis. Multivariate logistic regression analyses were used for the presence of SEs with a prevalence of $10 \%$ or higher. Data were analyzed using SPSS 15.0.

\section{Results}

Demographics and basic characteristics of the 846 subjects are presented in Table 1. Their mean age was 43.0 years and $67 \%$ was female. Thirty eight percent of the 927 cases had a co-morbid depression and anxiety disorder and 31\% used a benzodiazepine. SSRI use (63\%) mainly concerned paroxetine, fluoxetine, citalopram and escitalopram. TCA use included amitriptyline, nortriptyline and clomipramine. In $2.6 \%$ of the cases St John's wort was used.

In $64 \%$ of cases of antidepressant use, on average 2.9 SEs were reported. Absence of SEs was more common with SSRI use, as compared to venlafaxine use $(p=0.03)$ and, although not significantly, compared with TCA use $(p=0.10)$ (Table 2). No SEs were reported for alternative treatment with St John's wort.

The average prevalence of specific SEs ranged from $6 \%$ to $25 \%$. As compared to SSRIs, TCAs caused more typical anticholinergic SEs like constipation and dry mouth. As compared to SSRIs, the use of venlafaxine was associated with more muscle spasms/twitching, profuse sweating, sexual dysfunction and dizziness. Mirtazapine was associated with more sleepiness during the day and but less constipation and sexual dysfunction. In this univariate analysis we did not find a clear positive association between mirtazapine use and weight gain as compared to SSRIs.

\subsection{Determinants of SEs in multivariate analyses}

SE reporting was associated with depression severity and additional psychiatric diagnoses, TCA use and higher dosages. SE reporting was negatively associated with age, concurrent use of benzodiazepines and prolonged antidepressant use (Table 3). Analyses of comparing 'one or two SEs' and 'three or more SEs' vs. reporting 'no SEs' show consistency in the directions of these associations. Except for years of education, the analysis of 'three or more SEs' showed stronger associations.

In contrast with the univariate analysis, the use of TCAs was independently associated with more reporting of 'one 
Table 1 Baseline characteristics of antidepressant users $(n=846)$ and cases of antidepressant use $(n=927)$.

\begin{tabular}{|c|c|}
\hline $\begin{array}{l}\text { Number of antidepressant users } \\
\text { Sociodemographics }\end{array}$ & $n=846$ \\
\hline Gender (\% Female) & 67 \\
\hline Age (mean in years, SD) & $43(12)$ \\
\hline Years of education (mean in years, SD) & $12(3.3)$ \\
\hline $\begin{array}{l}\text { Number of cases of antidepressant use } \\
\text { Psychiatric status }\end{array}$ & $n=927^{a}$ \\
\hline MDD and Anxiety disorders (\%) & 38 \\
\hline MDD alone (\%) & 22 \\
\hline Anxiety disorders alone (\%) & 12 \\
\hline No current diagnosis (\%) & 28 \\
\hline Number of psychiatric diagnosis (mean, SD) & $1.8(1.5)$ \\
\hline Depression severity (mean IDS score, SD) & $24(13)$ \\
\hline Concurrent benzodiazepine use (\%) & 31 \\
\hline Alcohol dependence (\%) & 10.2 \\
\hline Alcohol abuse (\%) & 8.8 \\
\hline \multicolumn{2}{|l|}{ Antidepressant characteristics } \\
\hline $\begin{array}{l}\text { Selective serotonine reuptake inhibitors } \\
\text { (\%) }\end{array}$ & 63.0 \\
\hline Tricyclic antidepressants (\%) & 10.5 \\
\hline Venlafaxine (\%) & 15.6 \\
\hline Mirtazapine (\%) & 6.3 \\
\hline St John's wort (\%) & 2,6 \\
\hline Other antidepressants (\%) & 2.0 \\
\hline $\begin{array}{l}\text { Dose (median (IQR 25\%-75\%) } \\
\text { in Defined Daily Dose) }\end{array}$ & $\begin{array}{l}1.0 \\
(1.0-1.5)\end{array}$ \\
\hline $\begin{array}{l}\text { Duration of use (median (IQR 25\%-75\%) } \\
\text { in years) }\end{array}$ & $\begin{array}{l}1.0 \\
(0.4-2.0)\end{array}$ \\
\hline
\end{tabular}

or two SEs' and 'three or more SEs' as compared to SSRIs. Venlafaxine and mirtazapine did not show this difference.

Although females did not report more SEs, female gender was associated with more constipation and weight gain and with less sexual dysfunction (Table 4). Higher age was associated with less sleepiness during the day, less profuse sweating and less dizziness. Depression severity was associated with dizziness and anticholinergic SEs like constipation and dry mouth.

TCAs were associated with more anticholinergic SEs compared with SSRIs. Venlafaxine only differed from SSRIs in its association with more profuse sweating. Concurrent benzodiazepine use was associated with less profuse sweating. Compared with SSRIs, mirtazapine showed less sexual dysfunction and more weight gain. The dose of the antidepressant was associated with increased odds for most specific SEs with odds ratios between 1.1 and 1.5.

\section{Discussion}

This naturalistic study shows that patient-perceived SEs are common and persist during long-term antidepressant use in a large cohort of patients with depression and/or anxiety disorders. Our structured inventory of 12 common antidepressant SEs confirms the known differences in SE profiles among different types of antidepressants. However, it also shows venlafaxine to be associated with more profuse sweating compared with SSRIs. The number of reported SEs is higher at younger patient age, higher depression severity, more psychiatric diagnoses, higher antidepressant dose and shorter duration of use. Weight gain is associated with female gender and longer duration of use. Other specific SEs are associated with antidepressant dose and/or depression severity.

Our multivariate model (Table 3 ) indicates that SEs are more common with TCAs as compared to SSRI, whereas this difference is not shown for venlafaxine and mirtazapine. This is in line with a meta-analysis of many short-term clinical trials, where TCAs had inferior tolerability compared with SSRIs (Anderson, 2000). A meta-analysis of clinical trial data shows venlafaxine to be more efficacious and have more SEs compared with SSRIs (Schueler et al., 2011). Short-term prescription event monitoring in primary care setting shows no major differences in SE reporting (Mackay et al., 1999). In long-term use we now find no difference in the number of reported SEs between SSRI and venlafaxine. This is shown in a multivariate model, that includes the dose of the antidepressant. Hereby, we provide an intrinsic comparison between the types of antidepressants independent of the dose. This could provide an explanation for the differences found in clinical trials, where high dosages of venlafaxine were used to provide higher efficacy at the cost of decreased tolerability as compared to SSRIs (Schueler et al., 2011). In multivariate analysis, mirtazapine showed less sexual dysfunction and more weight gain when compared with SSRIs in long-term use. These are two important features of mirtazapine, which have previously been demonstrated in short-term studies (Watanabe et al., 2010).

In several long-term studies of Hypericum extracts (Kasper et al., 2010; Kasper et al., 2008), placebo level SEs are reported. We did not have a single report of SEs on the use of St John's wort preparations, but this could be due to the fact that these preparations were not licensed at the time of data collection and detailed information on preparation strengths and dosages used was not available. This alternative treatment was not prescribed by medical doctors and were only taken on the patient's own instigation, possibly resulting in easy discontinuation of treatment in case of side effects. In addition, the number of John's wort users in this sample was very small, limiting the interpretation of our findings regarding this sample.

In a short-term study, detailed information on the time course of SEs of escitalopram and nortriptyline has been published (Uher et al., 2009). Prevalence of drowsiness, headache, nausea and orthostatic dizziness dropped, whereas other SEs, particularly anticholinergic SEs and sexual dysfunction, persisted over the 12-week treatment course. In the present study we find slightly lower SE reporting with prolonged antidepressant use, while no associations are detected between specific SEs and prolonged use. During long-term antidepressant use, all specific SEs seem to persist.

In univariate analyses, anticholinergic SEs, like dry mouth and constipation, were reported more often with TCA use, compared with all other types of antidepressants. 
Table 2 Prevalence of side effects (SEs in \%) to different types of antidepressant $(n=927)$.

\begin{tabular}{|c|c|c|c|c|c|c|c|}
\hline Type of antidepressant & $\begin{array}{l}\text { SSRI } \\
n=584\end{array}$ & $\begin{array}{l}\text { TCA } \\
n=97\end{array}$ & $\begin{array}{l}\text { VEN } \\
n=145\end{array}$ & $\begin{array}{l}\text { MIR } \\
n=58\end{array}$ & $\begin{array}{l}\text { Overall } \\
p \text {-value }\end{array}$ & $\begin{array}{l}\text { SJW } \\
n=24\end{array}$ & $\begin{array}{l}\text { Other ADs } \\
n=19\end{array}$ \\
\hline \multicolumn{8}{|l|}{ Number of SEs per case } \\
\hline Zero SEs (\%) & $36^{a}$ & 28 & $27^{\mathrm{a}}$ & 36 & 0.09 & 100 & 47 \\
\hline One or two SEs (\%) & 33 & 33 & 37 & 40 & 0.55 & 0 & 26 \\
\hline Three or more SEs (\%) & 31 & 39 & 36 & 24 & 0.16 & 0 & 26 \\
\hline \multicolumn{8}{|l|}{ Type of SE } \\
\hline Sleeplessness (\%) & 7 & 5 & 10 & 5 & 0.50 & 0 & 16 \\
\hline Sleepiness during the day (\%) & 21 & $14^{\mathrm{a}}$ & 20 & $30^{\mathrm{a}}$ & 0.16 & 0 & 16 \\
\hline Restlessness (\%) & 9 & 6 & 10 & 12 & 0.64 & 0 & 11 \\
\hline Muscle spasms, twitching (\%) & $9^{a}$ & 12 & $15^{\mathrm{a}}$ & 7 & 0.09 & 0 & 5 \\
\hline Dry mouth $(\%)$ & $22^{\mathrm{a}}$ & $49^{\mathrm{a}, \mathrm{b}, \mathrm{c}}$ & $23^{b}$ & $22^{c}$ & $<0.001^{\mathrm{e}}$ & 0 & 16 \\
\hline Profuse sweating (\%) & $20^{\mathrm{a}}$ & $20^{\mathrm{b}}$ & $32^{a, b, c}$ & $14^{\mathrm{c}}$ & $0.01^{\mathrm{e}}$ & 0 & 11 \\
\hline Sexual dysfunction (\%) & $23^{a, b}$ & $20^{c}$ & $31^{a, c, d}$ & $10^{\mathrm{b}, \mathrm{d}}$ & $0.01^{\mathrm{e}}$ & 0 & 11 \\
\hline Nausea $(\%)$ & 10 & 4 & 9 & 5 & 0.16 & 0 & 11 \\
\hline Constipation (\%) & $8^{\mathrm{a}}$ & $20^{a, b, c}$ & $10^{\mathrm{b}, \mathrm{d}}$ & $2^{c, d}$ & $0.001^{e}$ & 0 & 0 \\
\hline Diarrhea (\%) & 7 & 4 & 5 & 5 & 0.58 & 0 & 0 \\
\hline Weight gain (\%) & 19 & 22 & 17 & 29 & 0.24 & 0 & 16 \\
\hline Dizziness $(\%)$ & $12^{\mathrm{a}}$ & 11 & $19^{\mathrm{a}}$ & 12 & 0.15 & 0 & 5 \\
\hline
\end{tabular}

$A D=$ antidepressant, $S E=$ side effect, $S S R I=$ selective serotonine reuptake inhibitor, $T C A=$ Tricyclic Antidepressant, VEN=Venlafaxine, MIR=Mirtazapine, SJW=St John's wort.

$\mathrm{a}, \mathrm{b}, \mathrm{c}, \mathrm{d}$ Difference in $\mathrm{SE}$ prevalence between two types of $\mathrm{AD}$ in univariate analysis, $p<0.05$.

${ }^{e}$ Difference in SE prevalence between SSRI, TCA, venlafaxine and mirtazapine, overall $p$-value $<0.05$.

Table 3 Adjusted odds ratios $(95 \% \mathrm{Cl})$ of multivariate analysis examining determinants to SE reporting $(n=884)$.

\begin{tabular}{|c|c|c|c|c|}
\hline & \multicolumn{2}{|c|}{ One or two SEs (vs. no SEs) } & \multicolumn{2}{|c|}{ Three or more SEs (vs. no SEs) } \\
\hline & OR $(95 \% \mathrm{Cl})^{\mathrm{a}}$ & $p$ & OR $(95 \% \mathrm{Cl})^{\mathrm{a}}$ & $p$ \\
\hline Female (vs. male) & $0.69(0.48-0.99)$ & 0.05 & $0.94(0.64-1.37)$ & 0.74 \\
\hline Age (per 10 years increase) & $0.86(0.74-1.00)$ & 0.06 & $0.83(0.71-0.97)$ & 0.02 \\
\hline Years of education (per year increase) & $1.06(1.00-1.12)$ & 0.04 & $1.03(0.97-1.08)$ & 0.39 \\
\hline Depression severity (per 10 points increase) & $0.94(0.80-1.11)$ & 0.48 & $1.28(1.09-1.51)$ & 0.002 \\
\hline \multicolumn{5}{|l|}{ Number of psychiatric diagnosis } \\
\hline No diagnosis & Ref & - & Ref & - \\
\hline One or two & $0.98(0.64-1.50)$ & 0.93 & $1.31(0.82-2.08)$ & 0.26 \\
\hline Three or more & $1.66(0.98-2.81)$ & 0.06 & $1.97(1.14-3.41)$ & 0.02 \\
\hline Concurrent benzodiazepine use & $0.73(0.49-1.06)$ & 0.10 & $0.64(0.43-0.94)$ & 0.02 \\
\hline \multicolumn{5}{|l|}{ Type of antidepressant } \\
\hline SSRI & Ref & - & Ref & - \\
\hline TCA & $2.02(1.10-3.68)$ & 0.02 & $2.52(1.39-4.60)$ & 0.003 \\
\hline Venlafaxine & $1.60(0.98-2.60)$ & 0.06 & $1.39(0.84-2.28)$ & 0.20 \\
\hline Mirtazapine & $1.42(0.73-2.77)$ & 0.30 & $0.93(0.44-1.96)$ & 0.84 \\
\hline Dose & $1.09(0.83-1.43)$ & 0.54 & $1.44(1.11-1.85)$ & 0.006 \\
\hline Duration of use (per year increase) & $0.97(0.92-1.02)$ & 0.22 & $0.94(0.89-1.00)$ & 0.04 \\
\hline
\end{tabular}

\footnotetext{
aBased on multinomial logistic regression analysis, adjusted for type of antidepressant (excluding 'St John's wort' and 'other antidepressants'), dose, duration of antidepressant use, gender, age, education, depression severity and number of psychiatric diagnosis.
}

In multivariate analyses, the dose of the antidepressant was associated with increased odds on overall SEs and specific SEs. These findings are well known from clinical trials and are therefore important markers of the validity of our findings in a naturalistic setting.
Elderly people generally are more sensitive to the toxic effects of psychotropic medication (Naranjo et al., 1995). In this patient group particular attention goes to the risk of adverse outcomes, like falls, fractures, upper gastrointestinal bleeding, epilepsy/seizures and hyponatremia 
Table 4 Adjusted odds ratios $(95 \% \mathrm{Cl})$ of multivariate analysis examining determinants to specific SEs $(n=884)$.

\begin{tabular}{|c|c|c|c|c|c|c|c|c|}
\hline \multirow[b]{2}{*}{ Prevalence } & \multicolumn{2}{|c|}{ Sleepiness during the day } & \multicolumn{2}{|c|}{ Muscle spasms/twitching } & \multicolumn{2}{|l|}{ Dry mouth } & \multicolumn{2}{|l|}{ Profuse sweating } \\
\hline & $20 \%$ OR $(95 \% \mathrm{Cl})^{\mathrm{a}}$ & $p$ & $20 \%$ OR $(95 \% \mathrm{Cl})^{\mathrm{a}}$ & $p$ & $25 \%$ OR $(95 \% \mathrm{Cl})^{\mathrm{a}}$ & $p$ & $22 \%$ OR $(95 \% \mathrm{Cl})^{\mathrm{a}}$ & $p$ \\
\hline Female (vs. male) & $0.83(0.58-1.18)$ & 0.30 & $0.97(0.60-1.57)$ & 0.91 & $1.17(0.83-1.64)$ & 0.38 & $0.98(0.69-1.39)$ & 0.89 \\
\hline Age (per 10 years increase) & $0.82(0.71-0.96)$ & 0.01 & $0.95(0.89-1.03)$ & 0.06 & $0.99(0.84-1.13)$ & 0.72 & $0.84(0.72-0.97)$ & 0.02 \\
\hline Years of education (per year increase) & $1.01(0.96-1.07)$ & 0.68 & $0.95(0.89-1.03)$ & 0.19 & $0.99(0.95-1.05)$ & 0.82 & $1.00(0.95-1.06)$ & 0.93 \\
\hline Depression severity (per 10 points increase) & $1.13(0.97-1.31)$ & 0.11 & $1.14(0.94-1.39)$ & 0.17 & $1.19(1.03-1.37)$ & 0.02 & $1.10(0.95-1.27)$ & 0.22 \\
\hline \multicolumn{9}{|l|}{ Number of psychiatric diagnosis } \\
\hline No diagnosis & Ref & - & Ref & - & Ref & - & Ref & - \\
\hline One or two & $1.50(0.92-2.45)$ & 0.11 & $1.26(0.66-2.41)$ & 0.48 & $1.09(0.70-1.70)$ & 0.70 & $1.08(0.68-1.69)$ & 0.75 \\
\hline Three or more & $1.91(1.10-3.32)$ & 0.02 & $1.11(0.53-2.32)$ & 0.78 & $1.29(0.78-2.13)$ & 0.33 & $1.31(0.78-1.22)$ & 0.30 \\
\hline Concurrent benzodiazepine use & $0.68(0.46-1.01)$ & 0.05 & $0.80(0.48-1.33)$ & 0.39 & $1.06(0.75-1.51)$ & 0.73 & $0.57(0.39-0.84)$ & 0.005 \\
\hline \multicolumn{9}{|l|}{ Type of antidepressant: } \\
\hline SSRI & Ref & - & Ref & - & Ref & - & Ref & - \\
\hline TCA & $0.81(0.44-1.52)$ & 0.52 & $2.01(0.99-4.07)$ & 0.05 & $4.00(2.49-6.43)$ & $<0.001$ & $1.36(0.77-2.39)$ & 0.29 \\
\hline Venlafaxine & $0.81(0.50-1.30)$ & 0.38 & $1.65(0.94-2.89)$ & 0.08 & $0.96(0.61-1.50)$ & 0.85 & $1.79(1.17-2.74)$ & 0.007 \\
\hline Mirtazapine & $1.75(0.93-3.28)$ & 0.08 & $0.93(0.32-2.72)$ & 0.89 & $1.09(0.56-2.12)$ & 0.80 & $0.78(0.35-1.72)$ & 0.53 \\
\hline Dose & $1.27(1.01-1.60)$ & 0.04 & $1.52(1.15-2.00)$ & 0.03 & $1.36(1.10-1.69)$ & 0.005 & $1.45(1.16-1.81)$ & 0.001 \\
\hline \multirow[t]{2}{*}{$\begin{array}{l}\text { Duration of use } \\
\text { (per year increase) }\end{array}$} & $0.98(0.92-1.04)$ & 0.47 & $0.94(0.86-1.03)$ & 0.20 & $0.97(0.92-1.02)$ & 0.23 & $0.98(0.92-1.03)$ & 0.40 \\
\hline & \multicolumn{2}{|l|}{ Sexual dysfunction } & \multicolumn{2}{|l|}{ Constipation } & \multicolumn{2}{|l|}{ Weight gain } & \multicolumn{2}{|l|}{ Dizziness } \\
\hline Prevalence & $23 \%$ OR $(95 \% \mathrm{Cl})^{\mathrm{a}}$ & $p$ & $10 \%$ OR $(95 \% \mathrm{Cl})^{\mathrm{a}}$ & $p$ & $20 \%$ OR $(95 \% \mathrm{Cl})^{\mathrm{a}}$ & $p$ & $13 \%$ OR $(95 \% \mathrm{Cl})^{\mathrm{a}}$ & $p$ \\
\hline Female (vs. male) & $0.49(0.35-0.68)$ & $<0.001$ & $3.18(1.71-5.92)$ & $<0.001$ & $1.76(1.19-2.59)$ & 0.004 & $0.72(0.47-1.10)$ & 0.13 \\
\hline Age (per 10 years increase) & $0.95(0.82-1.09)$ & 0.45 & $1.06(0.86-1.31)$ & 0.59 & $0.95(0.81-1.10)$ & 0.49 & $0.80(0.66-0.95)$ & 0.01 \\
\hline Years of education (per year increase) & $1.01(0.96-1.06)$ & 0.83 & $1.11(1.03-1.19)$ & 0.006 & $1.01(0.96-1.07)$ & 0.67 & $1.00(0.93-1.06)$ & 0.88 \\
\hline Depression severity (per 10 points increase) & $1.02(0.89-1.18)$ & 0.75 & $1.38(1.12-1.69)$ & 0.002 & $1.08(0.93-1.26)$ & 0.31 & $1.47(1.24-1.75)$ & $<0.001$ \\
\hline \multicolumn{9}{|l|}{ Number of psychiatric diagnosis } \\
\hline No diagnosis & Ref & - & Ref & - & Ref & - & Ref & - \\
\hline One or two & $1.68(1.07-2.66)$ & 0.03 & $1.31(0.66-2.59)$ & 0.44 & $0.99(0.63-1.56)$ & 0.97 & $1.37(0.75-2.50)$ & 0.31 \\
\hline Three or more & $1.64(0.96-2.79)$ & 0.07 & $1.08(0.49-2.34)$ & 0.86 & $1.05(0.62-1.77)$ & 0.87 & $1.13(0.57-2.22)$ & 0.73 \\
\hline Concurrent benzodiazepine use & $0.76(0.52-1.09)$ & 0.13 & $1.04(0.62-1.74)$ & 0.88 & $0.88(0.60-1.29)$ & 0.52 & $0.75(0.48-1.19)$ & 0.22 \\
\hline \multicolumn{9}{|l|}{ Type of antidepressant: } \\
\hline SSRI & Ref & - & Ref & - & Ref & - & Ref & - \\
\hline TCA & $0.91(0.52-1.60)$ & 0.74 & $3.18(1.67-6.06)$ & $<0.001$ & $1.29(0.74-2.25)$ & 0.36 & $1.08(0.53-2.18)$ & 0.85 \\
\hline Venlafaxine & $1.35(0.89-2.06)$ & 0.16 & $1.18(0.62-2.24)$ & 0.61 & $0.93(0.57-1.52)$ & 0.77 & $1.38(0.83-2.30)$ & 0.21 \\
\hline Mirtazapine & $0.36(0.15-0.88)$ & 0.03 & $0.22(0.03-1.65)$ & 0.14 & $2.32(1.24-4.35)$ & 0.009 & $0.99(0.42-2.34)$ & 0.99 \\
\hline Dose & $1.21(0.97-1.50)$ & 0.10 & $1.21(0.89-1.65)$ & 0.23 & $1.24(0.98-1.57)$ & 0.07 & $1.11(0.85-1.45)$ & 0.45 \\
\hline Duration of use (per year increase) & $1.01(0.96-1.07)$ & 0.69 & $0.93(0.85-1.02)$ & 0.11 & $1.06(1.01-1.11)$ & 0.03 & $0.97(0.90-1.05)$ & 0.43 \\
\hline
\end{tabular}

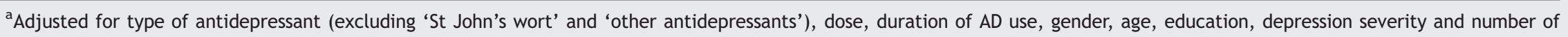
psychiatric diagnosis. 
(Draper and Berman, 2008; Coupland et al., 2011). However, looking at patient perceived SEs, in the present study SE reporting declines with age. Such a negative association with age is also found for several specific SEs, like sleepiness during the day, profuse sweating and dizziness. These results are in line with those obtained for the SSRI citalopram. For a range of specific SEs including headache, nausea, diarrhea and sweating, younger people of 18-64 years of age reported more SEs than patients older than 65 years (Barak et al., 2003). For serotonergic SEs, like nausea, diarrhea and sweating, this effect might be caused by the age-related reduction of sensitivity of the serotonergic system (Meltzer et al., 1998). However, a cohort study on short-term SSRI use involving more than 40,000 users, found no differences in SEs between the elderly ( $>70$ years) and younger patients ( $<70$ years) (Mackay et al., 1997). The present results on patient-perceived SEs during long-term use contribute to the on-going debate on the association between age and SEs.

Both depression severity and an increased number of psychiatric disorders are associated with increased overall SE reporting. Depression severity is also positively associated with specific SEs, like dry mouth, constipation and dizziness. The association of depression severity and SE reporting has been described previously in a short-term antidepressant trial (Uher et al., 2009) and for long-term lithium use (Wilting et al., 2009). Uher et al. showed that this association was not caused by confounding in the assessment of SEs and depression severity. A mechanism for perceiving and reporting more SEs by more severely disease-affected patients could be their increased sensitivity and attention to physical discomfort as has been observed with pain perception in depression (Klauenberg et al., 2008).

A recent meta-analysis showed large differences in weight gain between individuals as the result of treatment with various antidepressants (Serretti and Mandelli, 2010). In the present study female gender and prolonged antidepressant use are found to be associated with weight gain. However, this finding could be biased by the fact that part of the women might be more dissatisfied with their body weight and shape when compared to men (Rolls et al., 1991) and the natural tendency for people to get heavier over the years. Nevertheless, body weight increase as the result of antidepressant use should be monitored carefully as it is an important risk factor for the metabolic syndrome.

Profuse sweating can be very distressing and may cause impairment in social and occupational functioning. In the present study substantially more patients using venlafaxine experienced profuse sweating as compared with SSRI users. In a recent long-term efficacy study, sweating was reported in $16 \%$ of the patients after $8-20$ months of venlafaxine use at average dosages of $225 \mathrm{mg}$ a day, and $10 \%$ of the patients on fluoxetine at average dosages of $50 \mathrm{mg}$ a day (Thase et al., 2011). In our study, when specifically asked, profuse sweating was experienced in $32 \%$ of venlafaxine users and $20 \%$ of SSRI users. Due to our large study population this difference was statically significant both in univariate as well as multivariate analysis. High antidepressant dosages were also associated with increased odds for profuse sweating. This finding supports observations of SSRI-induced sweating resolving after dose reduction
(Marcy and Britton, 2005). In contrast with sweating as a side effect, low doses venlafaxine and paroxetine are effective in preventing sweating as a part of the treatment for vasomotor symptoms in menopausal women (Carroll and Kelley, 2009). The concurrent use of benzodiazepines was associated with less profuse sweating. In a small placebo controlled trial on hyperhydrosis in patients with a social anxiety disorder clonazepam was as efficacious as fluoxetine (Davidson et al., 2002). These data suggest that benzodiazepines may be helpful when hyperhydrosis triggered by psychosocial stressors emerges as SE in patients treated with antidepressants.

A strength of the present study is the use of the NESDA cohort which provides a large dataset on both clinical features of depression and anxiety including indicators of the CIDI diagnosis and severity of symptoms through validated scales. NESDA incorporates large groups of severely affected patients both with depression and anxiety disorders. These groups are often under-represented in large population-based surveys and in clinical trials. We used the same self-report structured SE ASEC-12 shortlist for all types of antidepressants. The assessment of patientperceived SEs by self-report has recently been validated against the psychiatrist rated UKU Side Effect Rating Scale (Uher et al., 2009). A few limitations need to be discussed. Because we did not define a specific time period in which the SEs should have occurred, severe side effects from earlier times could be measured due to re-call bias. All participants of the present study were familiar with the medication they used and were likely informed on possible SEs, which is known to influence SEs reporting (Rief et al., 2009). Moreover, due to the naturalistic setting, associations between SEs and type of antidepressant, dose and duration may have been weakened by routine clinical measures like lowering of dosages, switching and discontinuation of the antidepressant. We did not provide data on preceding antidepressant use. In case of short duration of antidepressant use, preceding use with an antidepressant from the same therapeutic class could, in theory, slightly lower the prevalence of class-specific side effects due to tolerance.

In conclusion, the present large naturalistic cohort study shows that during long-term use SEs to antidepressants are common. Known differences in SE profiles between various types of antidepressants observed in short-term studies are confirmed. In addition, as compared to SSRI treatment, venlafaxine was associated with more profuse sweating. Weight gain is associated with female gender and longer duration of use. Other specific SEs are associated with antidepressant dose and depression severity. Although prolonged antidepressant use is weakly associated with less SE reporting, clinicians should be aware that antidepressantinduced SEs are persistent. SEs should, therefore, be incorporated in the evaluation of ongoing antidepressant therapy.

\section{Role of the funding source}

The infrastructure for the NESDA study (www.nesda.nl) is funded through the Geestkracht program of the Netherlands Organisation for Health Research and Development (Zon-Mw, 
Grant no. 10-000-1002) and is supported by participating universities and mental health care organizations (VU Univer sity Medical Center, GGZ inGeest, Arkin, Leiden University Medical Center, GGZ Rivierduinen, University Medical Center Groningen, Lentis, GGZ Friesland, GGZ Drenthe, Scientific Institute for Quality of Healthcare (IQ healthcare), Nether lands Institute for Health Services Research (NIVEL) and Netherlands Institute of Mental Health and Addiction (Trimbos)).

The funders were not involved in the design or conduct of the study or in the collection, management, analysis, or interpretation of the data, or preparation, review, or approval of the manuscript.

\section{Contributors}

All authors contributed to the study design, discussions and manuscript revision. P.M. Bet performed the literature search, statistical analyses and wrote the first draft.

\section{Conflict of interest}

All authors declare that they have no conflict of interest.

\section{Acknowledgment}

None.

\section{References}

American Psychiatric Association, 2001. Diagnostic and Statistical Manual of Mental Disorders, fourth edition, Washington.

Anderson, I.M., 2000. Selective serotonin reuptake inhibitors versus tricyclic antidepressants: a meta-analysis of efficacy and tolerability. J. Affect. Disord. 58, 19-36.

Barak, Y., Swartz, M., Levy, D., Weizman, R., 2003. Age-related differences in the side effect profile of citalopram. Prog. Neuropsychopharmacol. Biol. Psychiatry 27, 545-548.

Carroll, D.G., Kelley, K.W., 2009. Use of antidepressants for management of hot flashes. Pharmacotherapy 29, 1357-1374.

Coupland, C., Dhiman, P., Morriss, R., Arthur, A., Barton, G., Hippisley-Cox, J., 2011. Antidepressant use and risk of adverse outcomes in older people: population based cohort study. BMJ $343, \mathrm{~d} 4551$

Davidson, J.R., Foa, E.B., Connor, K.M., Churchill, L.E., 2002. Hyperhidrosis in social anxiety disorder. Prog. Neuropsychopharmacol. Biol. Psychiatry 26, 1327-1331.

Draper, B., Berman, K., 2008. Tolerability of selective serotonin reuptake inhibitors: issues relevant to the elderly. Drugs Aging 25, 501-519.

Gartlehner, G., Thieda, P., Hansen, R.A., Gaynes, B.N., veaughGeiss, A., Krebs, E.E., Lohr, K.N., 2008. Comparative risk for harms of second-generation antidepressants: a systematic review and meta-analysis. Drug Saf. 31, 851-865.

Hansen, R., Gaynes, B., Thieda, P., Gartlehner, G., veaugh-Geiss, A., Krebs, E., Lohr, K., 2008. Meta-analysis of major depressive disorder relapse and recurrence with second-generation antidepressants. Psychiatr. Serv. 59, 1121-1130.

Kasper, S., Caraci, F., Forti, B., Drago, F., Aguglia, E., 2010. Efficacy and tolerability of Hypericum extract for the treatment of mild to moderate depression. Eur. Neuropsychopharmacol. 20, 747-765.

Kasper, S., Volz, H.P., Moller, H.J., Dienel, A., Kieser, M., 2008. Continuation and long-term maintenance treatment with
Hypericum extract WS 5570 after recovery from an acute episode of moderate depression-a double-blind, randomized, placebo controlled long-term trial. Eur. Neuropsychopharmacol. 18, 803-813.

Kessler, R.C., Andrews, G., Colpe, L.J., Hiripi, E., Mroczek, D.K., Normand, S.L., Walters, E.E., Zaslavsky, A.M., 2002. Short screening scales to monitor population prevalences and trends in non-specific psychological distress. Psychol. Med. 32, 959-976.

Kessler, R.C., Barker, P.R., Colpe, L.J., Epstein, J.F., Gfroerer, J.C., Hiripi, E., Howes, M.J., Normand, S.L., Manderscheid, R.W., Walters, E.E., Zaslavsky, A.M., 2003. Screening for serious mental illness in the general population. Arch. Gen. Psychiatry 60, 184-189.

Klauenberg, S., Maier, C., Assion, H.J., Hoffmann, A., Krumova, E.K., Magerl, W., Scherens, A., Treede, R.D., Juckel, G., 2008. Depression and changed pain perception: hints for a central disinhibition mechanism. Pain 140, 332-343.

Lingam, R., Scott, J., 2002. Treatment non-adherence in affective disorders. Acta Psychiatr. Scand. 105, 164-172.

Lingjaerde, O., Ahlfors, U.G., Bech, P., Dencker, S.J., Elgen, K., 1987. The UKU side effect rating scale. A new comprehensive rating scale for psychotropic drugs and a cross-sectional study of side effects in neuroleptic-treated patients. Acta Psychiatr. Scand. Suppl. 334, 1-100.

Mackay, F.J., Dunn, N.R., Wilton, L.V., Pearce, G.L., Freemantle, S.N., Mann, R.D., 1997. A comparison of fluvoxamine, fluoxetine, sertraline and paroxetine examined by observational cohort studies. Pharmacoepidemiol. Drug Saf. 6, 235-246.

Mackay, F.R., Dunn, N.R., Martin, R.M., Pearce, G.L., Freemantle, S.N., Mann, R.D., 1999. Newer antidepressants: a comparison of tolerability in general practice. Br. J. Gen. Pract. 49, 892-896.

Mann, R.D., Wilton, L.V., Pearce, G.L., Mackay, F.J., Dunn, N.R., 1997. Prescription-event monitoring (PEM) in 1996-a method of non-interventional observational cohort pharmacovigilance. Pharmacoepidemiol. Drug Saf. 6 (Suppl. 3), S5-S11.

Marcy, T.R., Britton, M.L., 2005. Antidepressant-induced sweating. Ann. Pharmacother. 39, 748-752.

Meltzer, C.C., Smith, G., DeKosky, S.T., Pollock, B.G., Mathis, C.A., Moore, R.Y., Kupfer, D.J., Reynolds III, C.F., 1998. Serotonin in aging, late-life depression, and Alzheimer's disease: the emerging role of functional imaging. Neuropsychopharmacology 18 , 407-430.

Naranjo, C.A., Herrmann, N., Mittmann, N., Bremner, K.E., 1995. Recent advances in geriatric psychopharmacology. Drugs Aging 7, 184-202.

Papanikolaou, P.N., Churchill, R., Wahlbeck, K., Ioannidis, J.P., 2004. Safety reporting in randomized trials of mental health interventions. Am. J. Psychiatry 161, 1692-1697.

Penninx, B.W., Beekman, A.T., Smit, J.H., Zitman, F.G., Nolen, W.A., Spinhoven, P., Cuijpers, P., De Jong, P.J., Van Marwijk, H.W., Assendelft, W.J., Van Der, M.K., Verhaak, P., Wensing, M., de, G. R., Hoogendijk, W.J., Ormel, J., van, D.R., 2008. The Netherlands Study of Depression and Anxiety (NESDA): rationale, objectives and methods. Int. J. Methods Psychiatr. Res. 17, 121-140.

Rief, W., Nestoriuc, Y., von Lilienfeld-Toal, A., Dogan, I., Schreiber, F., Hofmann, S.G., Barsky, A.J., Avorn, J., 2009. Differences in adverse effect reporting in placebo groups in SSRI and tricyclic antidepressant trials: a systematic review and meta-analysis. Drug Saf. 32, 1041-1056.

Rolls, B.J., Fedoroff, I.C., Guthrie, J.F., 1991. Gender differences in eating behavior and body weight regulation. Health Psychol. 70, 133-142.

Rush, A.J., Gullion, C.M., Basco, M.R., Jarrett, R.B., Trivedi, M.H., 1996. The Inventory of Depressive Symptomatology (IDS): psychometric properties. Psychol. Med. 26, 477-486.

Schueler, Y.B., Koesters, M., Wieseler, B., Grouven, U., Kromp, M., Kerekes, M.F., Kreis, J., Kaiser, T., Becker, T., Weinmann, S., 2011. A systematic review of duloxetine and venlafaxine in 
major depression, including unpublished data. Acta Psychiatr. Scand. 123, 247-265.

Serretti, A., Mandelli, L., 2010. Antidepressants and body weight: a comprehensive review and meta-analysis. J. Clin. Psychiatry 71, 1259-1272.

Stahl, S.M., Grady, M.M., Moret, C., Briley, M., 2005. SNRls: their pharmacology, clinical efficacy, and tolerability in comparison with other classes of antidepressants. CNS.Spectr. 10, 732-747.

Stone, M., Laughren, T., Jones, M.L., Levenson, M., Holland, P.C., Hughes, A., Hammad, T.A., Temple, R., Rochester, G., 2009. Risk of suicidality in clinical trials of antidepressants in adults: analysis of proprietary data submitted to US Food and Drug Administration. BMJ 339, b2880.

Thase, M.E., Gelenberg, A., Kornstein, S.G., Kocsis, J.H., Trivedi, M.H., Ninan, P., Li, T., Pedersen, R., Keller, M., 2011. Comparing venlafaxine extended release and fluoxetine for preventing the recurrence of major depression: results from the PREVENT study. J. Psychiatr. Res. 45, 412-420.

Trindade, E., Menon, D., Topfer, L.A., Coloma, C., 1998. Adverse effects associated with selective serotonin reuptake inhibitors and tricyclic antidepressants: a meta-analysis. CMAJ 159, 1245-1252.

Uher, R., Farmer, A., Henigsberg, N., Rietschel, M., Mors, O., Maier, W., Kozel, D., Hauser, J., Souery, D., Placentino, A., Strohmaier, J., Perroud, N., Zobel, A., Rajewska-Rager, A., Dernovsek, M.Z., Larsen, E.R., Kalember, P., Giovannini, C.,
Barreto, K.J., McGuffin, P., Aitchison, K.J., 2009. Adverse reactions to antidepressants. Br. J. Psychiatry 195, 202-210.

van der Lem, R., van der Wee, N.J., van, V.T., Zitman, F.G., 2011. The generalizability of antidepressant efficacy trials to routine psychiatric out-patient practice. Psychol. Med. 41, 1353-1363.

Watanabe, N., Omori, I.M., Nakagawa, A., Cipriani, A., Barbui, C., McGuire, H., Churchill, R., Furukawa, T.A., 2010. Safety reporting and adverse-event profile of mirtazapine described in randomized controlled trials in comparison with other classes of antidepressants in the acute-phase treatment of adults with depression: systematic review and meta-analysis. CNS Drugs 24, 35-53.

WHO, 2012. Collaborating Centre for Drug Statistics Methodology. Anatomical Therapeutic Chemical (ATC) Classification. 〈http:// www. whocc.no/atcddd/> (accessed May 2012).

Wilting, I., Heerdink, E.R., Mersch, P.P., den Boer, J.A., Egberts, A.C., Nolen, W.A., 2009. Association between lithium serum level, mood state, and patient-reported adverse drug reactions during longterm lithium treatment: a naturalistic follow-up study. Bipolar Disord. 11, 434-440.

Wittchen, H.U., 1994. Reliability and validity studies of the WHOComposite International Diagnostic Interview (CIDI): a critical review. J. Psychiatr. Res. 28, 57-84.

Zimmerman, M., Mattia, J.I., Posternak, M.A., 2002. Are subjects in pharmacological treatment trials of depression representative of patients in routine clinical practice? Am. J. Psychiatry 159, 469-473. 